\title{
Autoregulation of Brain Blood Flow during Hypotension and Hypertension in Infant Lambs
}

\author{
BRENT W. ARNOLD, CHRISTOPHER G. MARTIN, BENNY J. ALEXANDER, TAIMIN CHEN, \\ AND LAWRENCE R. FLEMING
}

Section of Neonatology, Department of Pediatrics, Baylor College of Medicine, Houston, Texas 77030

\begin{abstract}
To determine the limits of aortic blood pressure in infant lambs for autoregulation of global and regional brain blood flow, we studied 10 unsedated lambs during hypotension and $\mathbf{1 0}$ unsedated lambs during hypertension. In lambs 6 to $13 \mathrm{~d}$ old, we produced graded changes in aortic blood pressure by inflating a balloon occluder placed around either the inferior vena cava or the descending aorta. Using radiolabeled microspheres, we measured global and regional brain blood flow at the baseline, and then with each graded change in aortic blood pressure. In an additional step, we administered atropine to determine if its antimuscarinic properties alter the fall in brain blood flow with severe hypotension, or alter the rise in brain blood flow with severe hypertension. We concluded that in the unsedated infant lamb, global brain blood flow remains stable between mean aortic blood pressures of 6.0 to 10.0 $\mathrm{kPa}$ (45 to 82 torr), a range from approximately $38 \%$ below to $12 \%$ above normal mean aortic blood pressure. We noted that this autoregulatory range is essentially unchanged from that described for the fetal lamb at $80 \%$ of term gestation-even though the mean aortic blood pressure rises during this period of maturation by more than $2.7 \mathrm{kPa}$ (20 torr). We found that the lower limit of autoregulation varies among the different brain regions and is lowest in the thalamus, pons, and medulla. We saw little variation of the upper limit among the brain regions. Finally, we determined that atropine does not alter brain blood flow during severe hypotension or severe hypertension. Our results suggest that the proximity of resting aortic pressure to the limits of autoregulation may even make the neonate with an intact autoregulatory mechanism vulnerable to brain injury. (Pediatr Res 29: 110-115, 1991)
\end{abstract}

Autoregulation of brain blood flow-and failure of autoregulation-appears to play a central role in the genesis of brain injury in the newborn infant. Studies in infant dogs show that both the upper and the lower limits of arterial pressure for autoregulation of brain blood flow appear to increase along with mean arterial pressure during the maturation of the animal from infancy to adulthood (1-4). Strandgaard et al. (5) report that in the adult human, the lower limit of autoregulation shifts from $9.3 \mathrm{kPa}$ (70 torr) in normotension to $16 \mathrm{kPa}$ (120 torr) in chronic hypertension. The autoregulatory limits for the preterm and the term human, however, are not known; yet both the location and the form of brain injury change with gestational age $(6,7)$. For example, intraventricular hemorrhage and periventricular leukomalacia occur typically in the premature infant, whereas parasagittal cerebral injury and status marmoratus occur typically

Received July 17, 1990; accepted September 7, 1990.

Correspondence to: Christopher G. Martin, M.D., Department of Pediatrics, Baylor College of Medicine, I Baylor Plaza, Houston, TX 77030 in the term infant. Ischemic, hypertensive, and hypoxic insults, the state of development of the brain's vascular anatomy $(8,9)$, and failure of autoregulation $(10,11)$ are all implicated in the production of brain injury in the newborn infant. Another contributing factor to these lesions may be the proximity of the autoregulatory limits to the resting mean arterial pressure. If autoregulatory limits do not change with increasing gestational age to the same degree that the resting mean arterial pressure changes, then the neonate's vulnerability to brain injury from ischemia or hypertension may also change, even when the autoregulatory mechanism is intact.

Papile et al. (12) determined the autoregulatory range in fetal lambs at approximately $80 \%$ of term gestation and found it to be 6.0 to $10.7 \mathrm{kPa}$ (45 to 80 torr). Mean aortic blood pressure rises from approximately $7.3 \mathrm{kPa}$ (55 torr) in the fetus at $80 \%$ of term gestation to approximately $10.0 \mathrm{kPa}$ (75 torr) in the newborn lamb. Purves and James (13) used the ${ }^{133} \mathrm{Xe}$ clearance method in the newborn lamb to determine an autoregulatory range of 5.7 to $12.0 \mathrm{kPa}$ (43 to 90 torr) for grey matter and a range of 5.3 to $12.0 \mathrm{kPa}$ (40 to 90 torr) for white matter. However, Purves and James had a limited number of data points near the upper limit of autoregulation. Also, the xenon clearance method did not detail regional brain blood flow. Several studies (14-16 in other animal species have demonstrated regional variation of brain blood flow during hypoxemia, hypotension, and hypertension. Brubakk et al. (17) found that atropine, a cholinergic, muscarinic receptor blocker, prevented the rise in brain blood flow with acute hypertension in newborn piglets and apparently extended the upper limit of autoregulation. In our study, we set out to determine the upper and lower limits of aortic blood pressure for autoregulation of global and regional brain blood flow in the infant lamb. To study the effect of maturation on the limits of autoregulation, we compared the infant lamb's autoregulatory limits with those described for the preterm fetal lamb to see if the limits shift as resting mean aortic blood pressure rises during this period of maturation. To determine if the antimuscarinic properties of atropine alter brain blood flow when blood pressure varies, we infused atropine during severe hypotension or hypertension.

\section{MATERIALS AND METHODS}

Surgical procedure. We operated on 20 full-term mixed-breed lambs ranging from 3 to $8 \mathrm{~d}$ of age. We separated the lambs into two groups of 10 . After anesthetizing the lamb with halothane and nitrous oxide, we intubated the lamb's trachea and then placed the lamb on a piston-type respirator (no. 607, Harvard Apparatus Co., Millis, MA). Through a cutdown on the left hind limb, we inserted saline-filled polyvinyl chloride catheters and advanced them so that their tips were positioned in the descending aorta and in the inferior vena cava. We then performed a left thoracotomy, ligated the ductus arteriosus, and inserted catheters into the internal thoracic artery and left atrium. To reduce venous return to the heart and cause a decrease in aortic blood 
pressure in each lamb of the hypotension study, we placed a saline-filled silastic vascular occluder (In Vivo Metric Systems, Healdsburg, CA) around the inferior vena cava (immediately caudal to the right atrium). To increase blood pressure in the proximal aorta and in vessels of the head and neck in each lamb of the hypertension study, we placed the vascular occluder around the descending aorta (immediately caudal to the ductus arteriosus). We inserted a chest tube to permit evacuation of pleural fluid collections and then closed the lamb's chest. To monitor arterial pressure proximal to the aortic vascular occluder, we incised the skin immediately superior to the left humeral head and inserted a catheter into a branch of the left axillary artery. The lamb recovered for at least $3 \mathrm{~d}$ before we performed any experiments. For nourishment during the recovery period, we kept the lamb with its ewe. We gave the lamb s.c. nalbuphine hydrochloride postoperatively and on the day after surgery for analgesia. Also, we administered antibiotics parenterally for prophylaxis of infection.

Experimental protocol. On the day of the experiment, the lambs weighted 3.18 to $6.93 \mathrm{~kg}$ and were 6 to $13 \mathrm{~d}$ old. During the study, the animals rested unsedated and blindfolded while lying in a prone position in a sling. We studied the hypotensive group (10 lambs) and the hypertensive group (10 lambs) of lambs under four successive conditions: at baseline aortic blood pressure, during a moderate change in blood pressure, during a severe change in blood pressure, and after infusing atropine $(0.3 \mathrm{mg} /$ $\mathrm{kg}$ ) i.v. into the inferior vena cava during severe hypotension or hypertension. None of the animals experienced both hypotension and hypertension. Before making any measurements, we ensured that the lambs reached a steady state by waiting at least 1 min after achieving each blood pressure level, and waiting at least 5 min after infusing the atropine.

Physiologic measurements. We measured vascular pressures in the common brachiocephalic trunk, descending aorta, and left atrium using a strain gauge manometer $(\mathrm{P} 23 \mathrm{Db}$, Statham Instruments, Hato Rey, Puerto Rico) referenced to the level of the left atrium. We recorded these pressures continuously using a Grass 4-channel amplifier recorder (Model 7 Polygraph, Grass Instruments, Quincy, MA). After injecting each radionuclide, we measured the $\mathrm{pH}$ and the oxygen and carbon dioxide tensions of the blood samples obtained from the ascending aorta with a Radiometer Blood Gas Analyzer (PM 27, Radiometer, Copenhagen, Denmark). We used a microoximeter (OSM2, Radiometer) to measure oxygen saturation and the cyanomethemoglobin method to measure $\mathrm{Hb}$ in the blood samples from the ascending aorta. At the end of the experiment, we killed the lamb with $\mathrm{T}$ 61 Euthanasia Solution (Taylor Pharmacal Co., Decatur, IL).

Blood flow measurements. At each blood pressure condition, we measured brain blood flow using radiolabeled microspheres $(18,19)$. To make each measurement, we injected approximately $1 \times 10^{6}$ spheres of $15-\mu \mathrm{m}$ diameter labeled with one of six radionuclides $\left({ }^{113} \mathrm{Sn},{ }^{95} \mathrm{Nb},{ }^{141} \mathrm{Ce},{ }^{51} \mathrm{Cr},{ }^{85} \mathrm{Sr}\right.$, and ${ }^{46} \mathrm{Sc}$ ) (New England Nuclear, Boston, MA; Minnesota Mining and Manufacturing, Minneapolis, $\mathrm{MN}$ ) into the left atrium over a period of $15 \mathrm{~s}$. Simultaneous with the injection, we withdrew a reference blood sample from the ascending aorta using a dual syringe infusion-withdrawal pump (model no. 944, Harvard Apparatus Co.). During the baseline period, we withdrew the arterial sample at a rate of $3.88 \mathrm{~mL} / \mathrm{min}$, and we continued the withdrawal for $45 \mathrm{~s}$ after completing the injection of the microspheres. To ensure trapping of the microspheres when cardiac output was reduced, we withdrew the arterial blood sample at a rate of $1.94 \mathrm{~mL} / \mathrm{min}$ for a total of $5 \mathrm{~min}$ during the remaining three periods (20). We replaced the blood withdrawn with an equal volume of saline. When the study concluded, an autopsy ensured the adequate placement of catheters. We then removed the brain, which we weighed and fixed in formalin. Later, we dissected the brain into regions (cortex, white matter, thalamus, midbrain, cerebellum, pons, and medulla) and placed the brain regions into separate vials. We determined the activity of each radionuclide in the reference blood samples and the brain tissue using a sodiumiodide scintillation detector and a multichannel pulse-height analyzer. We verified the presence of an adequate number of microspheres (at least 500 microspheres for each reference and organ sample) (19) and used the surrogate organ reference method to calculate brain blood flow in $\mathrm{mL} / \mathrm{min} / 100 \mathrm{~g}$ of wet tissue $\left(\mathrm{cpm}=\right.$ counts $\left.\cdot \mathrm{min}^{-1}\right)$.

$$
\text { Brain blood flow }=\frac{\begin{array}{c}
\text { Brain tissue activity }(\mathrm{cpm}) . \\
(100 \mathrm{~g} \text { tissue })^{-1}
\end{array}}{\text { withdrawal rate }(\mathrm{mL} / \mathrm{min})}
$$

Data analysis. We used one-way analysis of variance for repeated measures to test for significance in each physiologic variable, and then used Sheffe's " $f$ " test to test for significant differences between the mean values of the variables at different blood pressure conditions $(21,22)$. We defined a $p$ value of $<0.05$ to be statistically significant. We listed the mean and the SEM for each of the variables (Table 1). We calculated arterial oxygen content from the oxygen saturation, the oxygen carrying capacity of $\mathrm{Hb}\left(1.36 \mathrm{~mL} \mathrm{O}_{2} / \mathrm{g} \mathrm{Hb}\right)$ and dissolved oxygen (23).

To determine if atropine altered brain blood flow during hypotension or hypertension, we used paired $t$ tests and, in addition, calculated the corresponding least squares linear regression lines for the severe and severe plus atropine periods for each group and compared the slopes and intercepts using analysis of covariance (22). Because atropine did not significantly alter brain blood flow during either severe hypotension or severe hypertension, we included the atropine data points in all of our calculations and graphs.

We used an iterative approach to linear regression analysis, paralleling the technique described by Vieth (24), to determine the limits of aortic blood pressure for autoregulation of brain blood flow. Our model assumes that there is a plateau region that is described by a line with a slope not significantly different than zero (observations within the autoregulatory range of brain blood flow) and two pressure-passive regions (observations falling below or above the limits of autoregulation of brain blood flow) that are described by two lines with slopes significantly different than zero. We analyzed the data from the two experimental groups separately by determining the best fit for two lines in the hypotension group (a plateau line and a pressure-passive line falling below the autoregulatory range) and two lines in the hypertension group (a plateau line and a pressure-passive line rising above the autoregulatory range). In each experimental group, we ordered the 40 pairs of observations ( $x_{i}=$ aortic pressure, $y_{i}=$ blood flow) so that $x_{1} \leq x_{2} \leq x_{3} \ldots \leq x_{40}$. For the first iteration in the hypotension group, we calculated the first regression line using observations $x_{1}, x_{2}$, and $x_{3}$, and the second regression line using the remaining observations, $x_{4} \ldots x_{40}$. For the next iteration, we used observations $x_{1} \ldots x_{4}$ for the first regression line and the remaining observations for the second line. For each subsequent iteration, we removed one additional observation from the second subset of the data (unless $x_{i}=x_{i+1}$ $=x_{i}+2$; then all observations having an equal value for $x$ were shifted simultaneously) and included it in the first subset and recalculated the regression lines. To determine the two best sets of regression lines for autoregulation of global and regional brain blood flow, we chose for the pressure-passive line the maximum $r$ values with slopes significantly different from zero. For the plateau line, we chose slopes that were not significantly different from zero. We located the lower and upper limits of autoregulation by determining the threshold point, the point where there is a step from one regression line to another. We analyzed the data of the hypertension study in a similar manner, and constructed the complete autoregulation graph (Fig. 1) by combining the plateau data points for both experimental groups to calculate a new regression line. Because several iterations yielded pairs of lines that approached the best fit, we indicated the ranges of 
Table 1. Physiologic measurements with hypotension and hypertension*

\begin{tabular}{|c|c|c|c|c|c|c|c|c|}
\hline & \multicolumn{2}{|c|}{ Pao } & \multirow[b]{2}{*}{ Heart rate } & \multirow[b]{2}{*}{$\mathrm{pH}$} & \multirow{2}{*}{$\begin{array}{l}\mathrm{PaO}_{2} \\
(\mathrm{kPa})\end{array}$} & \multirow{2}{*}{$\begin{array}{c}\mathrm{PaCO}_{2} \\
(\mathrm{kPa})\end{array}$} & \multirow{2}{*}{$\begin{array}{c}\mathrm{CaO}_{2} \\
(\mathrm{mmol} / \mathrm{L}) \\
\end{array}$} & \multirow{2}{*}{$\begin{array}{c}\mathrm{Hb} \\
(\mathrm{g} / \mathrm{L})\end{array}$} \\
\hline & $\mathrm{kPa}$ & torr & & & & & & \\
\hline \multicolumn{9}{|l|}{ Hypotension } \\
\hline Baseline & $9.7 \pm 0.4$ & $73 \pm 3$ & $191 \pm 9$ & $7.39 \pm 0.01$ & $10.1 \pm 0.1$ & $6.4 \pm 0.1$ & $3.9 \pm 0.2$ & $97 \pm 4$ \\
\hline Moderate hypotension & $6.5 \pm 0.1$ & $49 \pm 1 \dagger$ & $223 \pm 15$ & $7.38 \pm 0.01$ & $10.4 \pm 0.5$ & $6.0 \pm 0.1$ & $3.8 \pm 0.1$ & $94 \pm 2$ \\
\hline Severe hypotension & $4.3 \pm 0.3$ & $32 \pm 2 † \ddagger$ & $164 \pm 11 \ddagger$ & $7.36 \pm 0.02$ & $9.7 \pm 0.7$ & $5.7 \pm 0.1 \dagger$ & $3.7 \pm 0.2$ & $95 \pm 2$ \\
\hline Severe hypotension + atropine & $4.7 \pm 0.4$ & $35 \pm 3 t \ddagger$ & $239 \pm 18 \S$ & $7.36 \pm 0.03$ & $10.5 \pm 0.9$ & $5.2 \pm 0.3+\ddagger$ & $3.8 \pm 0.2$ & $96 \pm 4$ \\
\hline \multicolumn{9}{|l|}{ Hypertension } \\
\hline Baseline & $9.7 \pm 0.3$ & $73 \pm 2$ & $166 \pm 14$ & $7.39 \pm 0.02$ & $12.0 \pm 0.4$ & $6.1 \pm 0.1$ & $4.3 \pm 0.2$ & $104 \pm 5$ \\
\hline Moderate hypertension & $12.7 \pm 0.3$ & $95 \pm 2 \dagger$ & $143 \pm 12$ & $7.35 \pm 0.02$ & $11.9 \pm 0.4$ & $6.3 \pm 0.3$ & $4.2 \pm 0.3$ & $103 \pm 5$ \\
\hline Severe hypertension & $15.6 \pm 0.4$ & $117 \pm 3+\ddagger$ & $140 \pm 8$ & $7.32 \pm 0.02 \dagger \ddagger$ & $12.7 \pm 0.5$ & $6.3 \pm 0.3$ & $4.0 \pm 0.2 \dagger$ & $99 \pm 5 \dagger$ \\
\hline Severe hypertension + atropine & $15.9 \pm 0.3$ & $119 \pm 2+\ddagger$ & $247 \pm 4 \dagger \ddagger \S$ & $7.31 \pm 0.02 \dagger \ddagger$ & $11.9 \pm 0.4$ & $6.4 \pm 0.4$ & $3.9 \pm 0.3 \dagger \ddagger$ & $96 \pm 0.5 † \ddagger$ \\
\hline
\end{tabular}

* Values for physiologic variables are listed as the mean \pm SEM for 10 lambs in each of the study groups. Pao, mean aortic pressure; $\mathrm{PaO}_{2}$, arterial $\mathrm{O}_{2}$ tension; $\mathrm{PaCO}_{2}$, arterial $\mathrm{CO}_{2}$ tension; $\mathrm{CaO}_{2}$, arterial $\mathrm{O}_{2}$ content.

$\dagger$ Significantly different $(p<0.05$, Scheffe's " $\mathrm{f}$ " test) from the baseline period.

¥ Significantly different from moderate hypotension or hypertension.

$\S$ Significantly different from severe hypotension or hypertension.

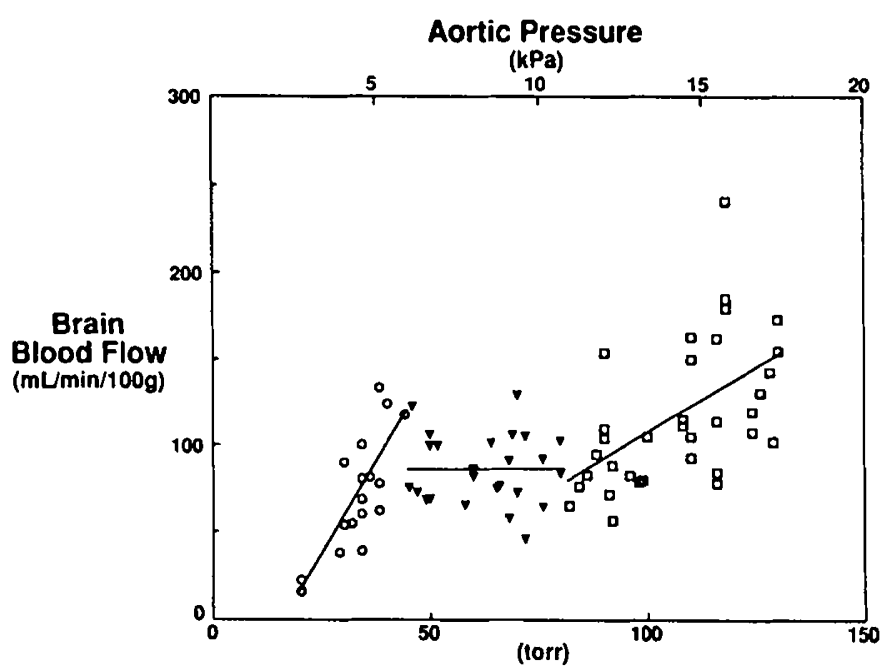

Fig. 1. Autoregulation of global brain blood flow with the hypotension group (inferior vena cava occlusion) and the hypertension group (descending aorta occlusion) combined. The equations for the regression line, the correlation coefficients $(r)$, and the probability $(p)$ that the slope of the regression line differs significantly from 0 are: $O, y=4.3 \times-69.9$, $r=0.79, p<0.0002$ for data falling below the lower limit $(6 \mathrm{kPa}, 44$ torr); $\nabla, \mathrm{y}=0.04 \times+86.5, r=0.03, p>0.91$ for data between the limits; and $\square, \mathrm{y}=1.5 \times-4, r=0.51, p<0.003$ for data above the upper limit (11 kPa, 82 torr) of autoregulation.

aortic blood pressure in which these lines were calculated for global and regional brain blood flow in the bar graph (Fig. 2).

\section{RESULTS}

Global brain blood flow remained stable until mean aortic blood pressure fell below $6.0 \mathrm{kPa}$ ( 45 torr), approximately $38 \%$ less than the mean aortic blood pressure at baseline, or rose above $10.0 \mathrm{kPa}$ (82 torr), approximately $12 \%$ greater than mean aortic blood pressure at baseline (Fig. 1) based on the best fit for the analyses. When the broadest boundaries for the limits of autoregulation of global brain blood flow were used (Fig. 2), the plateau region ranged from 5.3 to $12.3 \mathrm{kPa}$ (40 to 92 torr), $45 \%$ below and $26 \%$ above mean aortic pressure. With the groups combined, mean aortic blood pressure ranged from 2.7 to 17.3 $\mathrm{kPa}$ (20 to 130 torr). The lower limit of autoregulation varied among the different brain regions (Fig. 2). Our data suggest that the thalamus, pons, and medulla may be able to maintain stable blood flow better at lower aortic blood pressures than the remaining brain regions. The upper limit of autoregulation varied

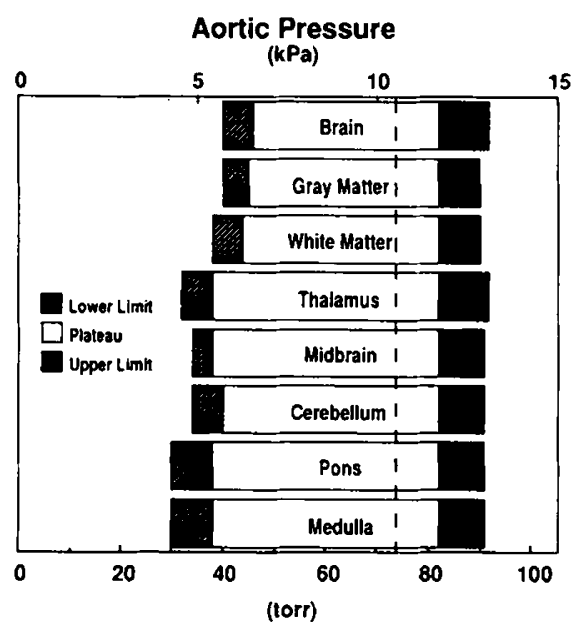

Fig. 2. Range of aortic pressures for the lower and upper limit of autoregulation of global and regional brain blood flow. Filled boxes display the range of pressure limits bounding the plateau region when regression analysis indicated that several lines had similar slopes, $r$, and $p$ values. The dashed line represents the average aortic pressure during the baseline period.

only slightly among the regions. Atropine did not alter brain blood flow significantly during either the severe hypotension period or the severe hypertension period.

Aortic blood pressure decreased significantly with moderate hypotension (33\% below baseline pressure) and decreased significantly again with severe hypotension ( $56 \%$ below baseline pressure, $35 \%$ below aortic pressure during moderate hypotension). However, because of our manipulations of the vascular occluder located around the inferior vena cava, aortic blood pressure did not change significantly between the periods of severe hypotension and severe hypotension plus atropine. Left atrial pressure fell from $0.3 \pm 0.1 \mathrm{kPa}(2 \pm 1$ torr $)$ at baseline to $-0.3 \pm 0.1 \mathrm{kPa}$ ( $-2 \pm 1$ torr) during moderate hypotension and remained unchanged during severe hypotension and severe hypotension plus atropine. Heart rate fell $26 \%$ from the moderate to the severe hypotension period, but this relative bradycardia reversed after infusing atropine. Arterial $\mathrm{pH}$, oxygen tension, $\mathrm{Hb}$, and oxygen content did not change significantly during progressive hypotension. Arterial carbon dioxide tension decreased significantly during the fall in aortic blood pressure.

Aortic blood pressure increased significantly with moderate hypertension (30\% above baseline pressure) and increased significantly again with severe hypertension $(60 \%$ above baseline pressure, $23 \%$ above aortic pressure during moderate hyperten- 
sion). Again, because of our manipulations of the vascular occluder, aortic blood pressure did not change significantly between the periods of severe hypertension and severe hypertension plus atropine. Descending aortic pressure, measured in four lambs, fell significantly from $9.9 \pm 0.4 \mathrm{kPa}(74 \pm 3$ torr) at baseline to $4.0 \pm 0.7 \mathrm{kPa}(30 \pm 5$ torr) during severe hypertension and increased significantly to $8.3 \pm 1.3 \mathrm{kPa}(62 \pm 10$ torr) after administration of atropine. Although descending aortic pressure decreased with initial balloon inflation during moderate hypertension, descending aortic pressure rose back toward baseline and proximal aortic pressure remained steady during measurement of brain blood flow. When averaged over the period of moderate hypertension, descending aortic pressure $(6.7 \pm 1.2$ $\mathrm{kPa}, 50 \pm 9$ torr) did not differ significantly from baseline. Left atrial pressure rose significantly from $0.3 \pm 0.1 \mathrm{kPa}(2 \pm 1$ torr $)$ during baseline to $1.2 \pm 0.1 \mathrm{kPa}(9 \pm 1$ torr $)$ during severe hypertension and fell significantly to $0.70 \pm 0.1(5 \pm 1$ torr $)$ after infusion of atropine. When blood pressure initially reached the desired level during severe hypertension, heart rate fell acutely from 166 at baseline at $129 \pm 9$ beats. $\mathrm{min}^{-1}$. However, after blood pressure had stabilized during moderate and severe hypertension, heart rate did not differ significantly from baseline (Table 1). As expected, heart rate rose markedly after i.v. infusion of atropine ( $49 \%$ from the baseline period, $76 \%$ from the severe hypertension period). With increasing hypertension, arterial $\mathrm{pH}$ decreased significantly. Arterial carbon dioxide and oxygen tensions, however, did not change significantly. Arterial oxygen content decreased significantly. This decrease was probably due to a small but significant decrease in $\mathrm{Hb}$ resulting from the withdrawal of blood.

\section{DISCUSSION}

Our results indicate that the lower and upper limits of aortic blood pressure for autoregulation of brain blood flow do not change in the lamb during its maturation from preterm fetus to infant. The limits that we found in the 1- to 2-wk-old infant lamb are essentially the same as those described by Papile et al. (12) (6 to $11 \mathrm{kPa}, 45$ to 80 torr) for the fetus at $80 \%$ of term gestation. However, mean aortic blood pressure rises during this 5- to 6-wk period from approximately $7 \mathrm{kPa}$ ( 55 torr) in the fetus to $10 \mathrm{kPa}$ ( 73 torr) for the lambs in our study. Autoregulation serves as a protective mechanism that maintains brain blood flow steady over a wide range of arterial pressures. Because the resting mean aortic blood pressure of the fetal lamb at $80 \%$ of term gestation is closer to the lower limit of cerebral autoregulation than to the upper limit, the data of Papile et al. (12) suggest that a fetus of this age is potentially more vulnerable to an ischemic insult than a hypertensive one. Because we did not find an increase in the autoregulatory limits to correspond with the increase that occurs in resting mean aortic blood pressure, our data suggest that the infant lamb of 1 to $2 \mathrm{wk}$ of age is potentially more vulnerable to a hypertensive insult than to an ischemic one.

Whether or not a similar relationship between brain autoregulation limits and aortic blood pressure exists in humans during the same phase of maturation is not known. Mean aortic blood pressure nearly doubles during the maturation from the verylow-birth-weight infant to the full-term infant $(26,27)$. Lou et al. $(10,11)$ suggested that in the fetus or newborn with asphyxia or respiratory distress syndrome there is a failure of autoregulation. Our results, however, suggest that even when autoregulation is intact, the infant may still be vulnerable to an ischemic or hypertensive insult because of the proximity of resting mean aortic blood pressure to one of the autoregulatory limits. When preterm infants undergo routine procedures such as weighing, examinations, or echocardiograms, blood pressure increases by approximately 1.5 to $5 \mathrm{kPa}$ (10 to 36 torr) on the average (28). In parallel to our findings, Perry et al. (28) suggest that the episodic elevations in blood pressure during interventions or spontaneous activity may exceed the limits of blood pressure stability and may predispose very-low-birth-weight infants to hemorrhagic brain injury.

Our findings that the brainstem and thalamic nuclei have the lowest limits for autoregulation of brain blood flow in the infant lamb are consistent with the findings of Laptook et al. (15), who observed that blood flow is better preserved in the brainstem and cerebellum than in the cerebrum during hemorrhagic hypotension in the newborn piglet. Pasternak and Groothuis (16) found regional variation of brain blood flow in phenylephrine-induced hypertension in newborn beagle puppies. We found, however that in the infant lamb there is little regional variation of the upper limit when pressure is altered by mechanical means.

Although metabolic and myogenic mechanisms are likely to be primarily responsible for the autoregulatory phenomenon (29), neural mechanisms may modify brain blood flow via activation of adrenergic or cholinergic nerves innervating cerebral vessels. The presence of both adrenergic and cholinergic nerves has been demonstrated in both extraparenchymal and intraparenchymal cerebral vessels (30-35). Although adrenergic nerves supplying cerebral vessels originate predominantly from the superior cervical ganglia (36), the ganglia from which cholinergic nerves arise have not been identified conclusively. Apparently, neither adrenergic nor cholinergic nerves play a major role in regulating brain blood flow during normotension (36-38). However, stimulation or reflex activation of adrenergic nerves: 1 ) constricted large cerebral arteries and increased large cerebral artery resistance while total cerebrovascular resistance remained unchanged $(39) ; 2$ ) blunted the transient vasodilation produced by acute, moderate hypertension $(40) ; 3$ ) greatly attenuated the increase in brain blood flow (41) and protected the blood brain barrier (42) during acute, severe hypertension; and 4) caused a small but significant reduction in brain blood flow during hemorrhagic hypotension in dogs (43). In newborn pigs, pial arteries constricted when adrenergic nerves were electrically stimulated (44). In addition, activation of adrenergic nerves in newborn dogs caused vasoconstriction during asphyxia (45) and limited the increase in brain blood flow during seizures to the hemibrain with intact innervation in newborn lambs (46). However, reflex activation of adrenergic nerves during hypoxia in newborn lambs did not alter cerebral blood flow despite the presence of functional adrenergic innervation of the cerebral circulation (47). Whether reflex activation of adrenergic nerves plays a major or minor role in fixing the autoregulatory limits in newborn animals has not been demonstrated. Although our study did not address this question, the pathways involved in reflex activation of adrenergic nerves, including baroreceptors and chemoreceptors, remained intact. The role of the cholinergic nervous system in control of the cerebral circulation remains unclear due to the uncertainty regarding the origin of cholinergic nerves innervating cerebral arteries and the inability to stimulate, ablate or inhibit these nerves. Therefore, information indicating effects of cholinergic nerves is based on direct application or infusion of cholinergic agonists or antagonists. The primary effect of acetylcholine, or muscarinic cholinergic agonists, on cerebral arteries both in vitro and in vivo in mature animals is vasodilation that depends on an intact endothelium and is reversed by atropine $(38,48$, 49). Acetylcholine causes contraction at high concentrations in vitro (48) or when the endothelium is injured (50). The response in immature animals varies depending on the species. Acetylcholine dilates the cerebral vessels of fetal and newborn lambs after topical application (51). In contrast, acetylcholine constricts cerebral arteries at high concentrations, elicits variable responses in cerebral vascular tone at lower concentrations, and increases release of both dilator and constrictor prostanoids into the cerebrospinal fluid in newborn pigs (52-54); acetylcholine contracts the cerebral vessels of newborn baboons (55). Information indicating effects of cholinergic nerves on autoregulation of brain blood flow in immature animals is limited. Brubakk et al. (17) noted that atropine prevented the rise in brain blood flow ob- 
served when aramine infusion caused systemic hypertension in newborn pigs. Atropine may have extended the upper limit of autoregulation when the pigs became hypertensive by blocking muscarinic, cholinergic receptors and inhibiting endotheliumdependent vasodilation induced by acetylcholine. However, this explanation for extension of the upper limit of autoregulation by atropine is not likely, inasmuch as direct application of acetylcholine predominantly constricts the cerebral arteries of newborn pigs $(52,53)$. Furthermore, acute hypertension causes endothelial injury and generation of superoxide, and impairs the endothelium-dependent vasodilation induced by acetylcholine (56). Another possible mechanism for extension of the upper limit of autoregulation by atropine in newborn pigs involves modulation of norepinephrine release by cholinergic nerves (57). By blocking the inhibitory effect of cholinergic activation on norepinephrine release, atropine may have augmented adrenergic vasoconstriction during hypertension. In contrast, we found no effect of atropine infusion on brain blood flow during severe hypertension or severe hypotension in this study. Disparities in our results and those of Brubakk et al. (17) may reflect differences in the species studied or the timing of atropine administration (i.e. before or during blood pressure perturbation).

To alter blood pressure in our study, we chose to use a mechanical device rather than pharmacologic agents to avoid the possibility of a direct effect of the drug on the cerebral circulation. Although many drugs have no detectable effects on cerebral blood flow when the blood brain barrier is intact, severe blood pressure alterations open the blood brain barrier (58) and may permit penetration of the drug to the vascular smooth muscle. On the other hand, mechanical devices that obstruct jugular venous return could modify the autoregulatory response of the cerebral circulation by raising cerebral venous pressure. Furthermore, cerebral venous hypertension opens the blood brain barrier (59). To produce hypotension, we placed the balloon occluder around the inferior vena cava rather than around the superior vena cava and avoided jugular venous obstruction and changes in sagittal venous pressure. All hypertensive or hypotensive stresses, whether pharmacologic, mechanical, or pathophysiologic, trigger reflex responses by stimulation or suppression of baro-, chemo-, and mechanoreceptors, by excitation or inhibition of CNS vasomotor centers, alterations in sympathetic and parasympathetic tone, and modulation of release of vasoactive hormones that attempt to reestablish homeostasis in the intact organism. Some of these responses may have direct effects on the cerebral circulation. For example, activation of sympathetic nerves produces a relative reduction in brain blood flow during hemorrhagic hypotension or acute hypertension and circulating vasopressin selectively dilates large cerebral arteries and reduces microvascular pressure without changing brain blood flow (60). We attempted to minimize any interference due to the methods used to alter blood pressure with these reflex responses. Because reducing carotid arterial pressure by obstruction of the brachiocephalic trunk or carotid arteries would trigger divergent reactions by loading baro- and mechanoreceptors proximal to the site of obstruction while unloading baroreceptors and stimulating chemoreceptors distally, we created hypotension by obstruction of venous return through the inferior vena cava. During hypertension, it is likely that the rise in afferent impulses from baroreceptors in the brachiocephalic trunk and carotid arteries would override the fall in impulses from large arteries distal to the occluder placed around the descending aorta because baroreceptors are most abundant in the walls of the carotid arteries and the brachiocephalic trunk and it is likely that the increase in afferent impulses from these receptors would cause a net reduction in adrenergic tone and an increase in vagal tone. An increase in vagal tone probably caused the initial decrease in heart rate after partial occlusion of the descending aorta. In contrast, surgical denervation of aortic and carotid baroreceptors causes intense sympathetic stimulation acutely and reduced cerebral blood flow in adult animals (43). Therefore, denervation of aortic and carotid baroreceptors may have altered the autoregulatory response in fetal lambs (12) for two reasons: 1) sympathetic stimulation due to denervation may have persisted during the study on the first postoperative day and 2) denervation of baroreceptors may have inhibited reflex activation of sympathetic and parasympathetic nerves during fluctuations in arterial pressure. In our study, we limited surgical dissection of the great vessels to the descending aorta at and just distal to the ductus arteriosus for placement of the balloon occluder and ligation of the ductus arteriosus. Explanations for the gradual rise in aortic pressure distal to the occluder during balloon inflation include release of renin and angiotensin triggered by decreased renal blood flow, fluid shifts from the interstitial compartment into the circulation, and increased cardiac output due to the gradual rise in heart rate after initial balloon inflation. Because angiotensin II does have small but detectable effects on brain blood flow when blood pressure remains stable (60), release of angiotensin II during aortic occlusion may have altered brain blood flow. However, any reduction in brain blood flow during aortic occlusion would have shifted the upper limit of autoregulation to a higher pressure threshold. Furthermore, elevation of left atrial pressure during hypertension due to aortic occlusion is likely to have stimulated release of atrial natriuretic factor. Because atrial natriuretic factor suppresses both the renin-angiotensin system and aldosterone release (61), it is likely that the reflex effects due to hypertension would have minimized the divergent effects on release of vasoactive hormones due to hypotension distal to the aortic occluder.

Arterial carbon dioxide tension and arterial oxygen content are potent regulators of brain blood flow (62-65). The fall in arterial carbon dioxide tension that occurred during severe hypotension may have exacerbated a fall in brain blood flow due to reduced arterial pressure. However, when we excluded from analysis animals that demonstrated the largest decreases in arterial carbon dioxide tension, the lower autoregulatory limit remained unchanged. The small, but significant decrease in arterial oxygen content that occurred during severe hypertension remained well within the normal range of arterial oxygen content for infant lambs $(62,66)$.

In summary, global brain blood flow remained stable in the infant lamb until mean aortic blood pressure fell below $6 \mathrm{kPa}$ (45 torr), or rose above $10 \mathrm{kPa}$ ( 82 torr). The resting mean aortic blood pressure of $9.7 \mathrm{kPa}$ ( 73 torr) was much closer to the upper autoregulatory limit than to the lower limit. We found no evidence to suggest a shift in the autoregulatory limits from those described for the fetus at $80 \%$ of term gestation. Because mean aortic blood pressure increases during this period of maturation, the proximity of each limit to the resting mean aortic blood pressure changes during the development from the preterm fetus to the infant lamb. The upper limits for autoregulation varied only slightly among the different brain regions, but the lower limits varied to a greater degree, and were lowest in the thalamic nuclei and brainstem. Atropine did not alter the fall in brain blood flow during severe hypotension or the rise during severe hypertension. Our data suggest that although failure of autoregulation is often implicated as a cause of ischemic or hypertensive brain injury in the neonate, the relationship of resting mean aortic blood pressure to each autoregulatory limit might even make the neonate with an intact autoregulatory mechanism vulnerable to injury.

Acknowledgments. The authors thank Drs. Jan GoddardFinegold and Thomas Hansen for their critical review of the manuscript and Madeline Fleming for her editorial assistance.

\section{REFERENCES}

1. Hernandez MJ, Brennan RW, Bowman GS 1980 Autoregulation of cerebral blood flow in the newborn dog. Brain Res 184:199-202

2. Rapela CE, Green HD 1964 Autoregulation of canine cerebral blood flow. Circ Res 24(suppl):205-212 
3. Harper AM 1966 Autoregulation of cerebral blood flow: influence of the arterial blood pressure on the blood flow through the cerebral cortex. J Neurol Neurosurg Psychiatry 29:398-403

4. Haggendal E, Johansson B 1965 Effects of arterial carbon dioxide tension and oxygen saturation on cerebral blood flow autoregulation in dogs. Acta Physio Scand 66(suppl):27-53

5. Strandgaard S, Olesen JM, Skinhøj E, Lassen NA 1973 Autoregulation of brain circulation in severe arterial hypertension. Br Med J 1:507-510

6. Volpe JJ 1987 Neurology of the Newborn. WB Saunders, Philadelphia, pp 159-361

7. MacDonald HM, Mulligan JC, Allen AC, Taylor PM 1980 Neonatal asphyxia I. Relationship of obstetric and neonatal complications to neonatal mortality in 38,405 consecutive deliveries. J Pediatr 96:898-902

8. Hambleton G, Wigglesworth JS 1976 Origin of intraventricular haemorrhage in the preterm infant. Arch Dis Child 51:651-659

9. Lou HC 1988 The "lost autoregulation hypothesis" and brain lesions in the newborn-an update. Brain Dev 10:143-146

10. Lou HC, Lassen NA, Friis-Hansen B 1979 Impaired autoregulation of cerebra blood flow in the distressed newborn infant. J Pediatr 94:118-121

11. Lou HC, Lassen NA, Tweed WA, Jones M, Palahniuk RJ 1970 Pressure passive cerebral blood flow and breakdown of the blood-brain barrier in experimental fetal asphyxia. Acta Paediatr Scand 68:57-63

12. Papile L, Rudolph AM, Heymann MA 1985 Autoregulation of cerebral blood flow in the preterm fetal lamb. Pediatr Res 19:159-161

13. Purves MJ, James IM 1969 Observations on the control of cerebral blood flow in the sheep fetus and newborn lamb. Circ Res 25:651-667

14. Cavazzuti M, Duffy TE 1982 Regulation of local cerebral blood flow in norma and hypoxic newborn dogs. Ann Neurol 11:247-257

15. Laptook A, Stonestreet BS, Oh W 1982 Autoregulation of brain blood flow in the newborn piglet: regional differences in flow reduction during hypotension. Early Hum Dev 6:99-107

16. Pasternak JF, Groothuis DR 1985 Autoregulation of cerebral blood flow in the newborn beagle puppy. Biol Neonate 48:100-109

17. Brubakk A, Bratlid D, Oh W, Yao AC, Stonestreet BS 1984 Atropine prevents increases in brain blood flow during hypertension in newborn piglets. Pediat Res 18:1121-1126

18. Lou HC, Lassen NA, Friis-Hansen B 1977 Low cerebral blood flow in hypotensive perinatal distress. Acta Neurol Scand 56:343-352

19. Buckberg GD, Luck JC, Payne DB, Hoffman JIE, Archie JP, Fixler DE 197 Some sources of error in measuring regional blood flow with radioactive microspheres. J Appl Physiol 31:598-604

20. Koehler RC, Chandra N, Guerci AD, Tsitlik J, Traystman RJ, Rogers MC Weisfeldt ML 1983 Augmentation of cerebral perfusion by simultaneous chest compression and lung inflation with abdominal binding after cardiac arrest in dogs. Circulation 67:266-275

21. Glantz SA 1987 Primer of Biostatistics. McGraw-Hill, New York, pp 245-277

22. Zar JH 1974 Biostatistical Analysis. Prentice-Hall, Englewood Cliffs, NJ, pp $130-248$

23. Sidi D, Kuipers JRG, Teitel D, Heymann MA, Rudolph AM 1983 Developmental changes in oxygenation and circulatory responses to hypoxemia in lambs. Am J Physiol 245:H674-H682

24. Vieth E 1989 Fitting piecewise linear regression functions to biological responses. J Appl Physiol 67:390-396

25. Deleted in proof

26. Kitterman JA, Phibbs RH, Tooley WH 1969 Aortic blood pressure in normal newborn infants during the first 12 hours of life. Pediatrics 44:959-968

27. Versmold HT, Kitterman JA, Phibbs RH, Gregory GA, Tooley WH 1981 Aortic blood pressure during the first 12 hours of life in infants with birth weight 610 to 4,220 grams. Pediatrics 67:607-613

28. Perry EH, Bada HS, Ray JD, Korones SB, Arheart K, Magill HL 1990 Blood pressure increases, birth weight-dependent stability boundary, and intraventricular hemorrhage. Pediatrics 85:727-732

29. Busija DW, Heistad DD 1984 Factors involved in the physiological regulation of the cerebral circulation. Rev Physiol Biochem Pharmacol 101:162-211

30. Kobayashi S, Tsukahara S, Sugita K, Nagata T 1981 Adrenergic and cholinergic innervation of rat cerebral arteries. Histochemistry 70:129-138

31. Harik SI, Sharma VK, Wetherbee JR, Warren RH, Banerjee SP 1981 Adrenergic and cholinergic receptors of cerebral microvessels. J Cereb Blood Flow Metab 1:329-338

32. Bevan JA, Duckworth J, Laher I, Oriowo MA, McPherson GA, Bevan RD 1987 Sympathetic control of cerebral arteries: specialization in receptor type, reserve, affinity, and distribution. FASEB J 1:193-198

33. Florence VM, Bevan JA 1979 Biochemical determinations of cholinergic innervation in cerebral arteries. Circ Res 45:217-218

34. Estrada C, Hamel E, Krause DN 1983 Biochemical evidence for cholinergic innervation of intracerebral blood vessels. Brain Res 266:261-270

35. Arneric SP, Honig MA, Milner TA, Greco S, ladecola C, Reis DJ 1988 Neuronal and endothelial sites of acetylcholine synthesis and release associated with microvessels in rat cerebral cortex: u!trastructural and neurochemical studies. Brain Res 454:11-30

36. Mueller SM, Heistad DD, Marcus ML 1977 Total and regional cerebral blood flow during hypotension, hypertension and hypocapnia: effect of sympathetic denervation in dogs. Circ Res 41:350-356

37. Busija DW, Marcus ML, Heistad DD 1982 Pial artery diameter and blood flow velocity during sympathetic stimulation in cats. J Cereb Blood Flow Metab 2:363-367

38. Kuschinsky W, Wahl M, Neiss A 1974 Evidence for cholinergic dilatatory receptors in pial arteries of cats. Pflugers Arch 347:199-208

39. Baumbach GL, Heistad DD 1983 Effects of sympathetic stimulation and changes in arterial pressure on segmental resistance of cerebral vessels in rabbits and cats. Circ Res 52:527-533

40. Busija DW, Heistad DD, Marcus ML 1980 Effects of sympathetic nerves on cerebral vessels during acute, moderate increases in arterial pressure in dogs and cats. Circ Res 46:696-702

41. Heistad DD, Marcus ML, Gross PM 1978 Effects of sympathetic nerves on cerebral vessels in dog, cat, and monkey. Am J Physiol 235:H544-HS52

42. Bill A, Linder J 1976 Sympathetic control of cerebral blood flow in acute arterial hypertension. Acta Physiol Scand 96:114-121

43. Gross PM, Heistad DD, Strait MR, Marcus ML, Brody MJ 1979 Cerebral vascular responses to physiological stimulation of sympathetic pathways in cats. Circ Res 44:288-294

44. Busija DW, Leffler CW, Wagerle LC 1985 Responses of newborn pig pial arteries to sympathetic nervous stimulation and exogenous norepinephrine. Pediatr Res 19:1210-1214

45. Hernandez MJ, Hawkins RA, Brennan RW 1980 Changes in neonatal cerebral circulation during asphyxia: evidence of sympathetic mediation. Physiologist 23:11A(abstr)

46. Kurth CD, Wagerle LC, Delivoria-Papadopoulos M 1988 Sympathetic regulation of cerebral blood flow during seizures in newborn lambs. Am J Physiol 255:H563-H568

47. Wagerle LC, Hefferman TM, Sacks LM, Delivoria-Papadopoulos M 1983 Sympathetic effect on cerebral blood flow regulation in hypoxic newborn lambs. Am J Physiol 245:H487-H494

48. Lee TJ, Kinkead LR, Sarwinske S 1982 Norepinephrine and acetylcholine transmitter mechanisms in large cerebral arteries of the pig. J Cereb Blood Flow Metab 2:439-450

49. Busija DW, Heistad DD 1982 Atropine does not attenuate cerebral vasodilatation during hypercapnia. Am J Physiol 242:H683-H687

50. Rosenblum WI 1986 Endothelial dependent relaxation demonstrated in vivo in cerebral arterioles. Stroke 17:494-497

51. Wagerle LC, Kurth CD, Busija DW, Roth RA, Delivoria-Papadopoulos M 1990 Development of cholinergic mechanisms in the cerebral arteries of fetal and newborn lambs. Pediatr Res 27:66A(abstr)

52. Wagerle LC, Busija DW 1989 Cholinergic mechanisms in the cerebral circulation of the newborn piglet: effect of inhibitors of arachidonic acid metabolism. Circ Res 64:1030-1036

53. Armstead WM, Mirro R, Busija DW, Leffler CW 1989 Permissive role of prostanoids in acetylcholine-induced cerebral vasoconstriction. J Pharmaco Exp Ther 251:1012-1019

54. Busija DW, Wagerle LC, Pourcyrous M, Lemler CW 1988 Acetylcholine dramatically increases prostanoid synthesis in piglet parietal cortex. Brain Res 439:122-126

55. Hayashi S, Park MK, Kuehl TJ 1984 Higher sensitivity of cerebral arteries isolated from premature and newborn baboons to adrenergic and cholinergic stimulation. Life Sci 35:253-260

56. Wei EP, Kontos HA, Christman CW, DeWitt DS, Povlishock JT 1985 Superoxide generation and reversal of acetylcholine-induced cerebral arteriolar dilation after acute hypertension. Circ Res 57:781-787

57. Duckles SP, Kennedy CD 1982 Cerebral blood vessels: effects of exogenous acetylcholine and field stimulation on norepinephrine release. J Pharmacol Exp Ther 222:562-565

58. Mayhan WG, Faraci FM. Heistad DD 1986 Disruption of the blood-brain barrier in cerebrum and brain stem during acute hypertension. Am J Physiol 251:H1171-H1175

59. Mayhan WG, Heistad DD 1986 Role of veins and cerebral venous pressure in disruption of the blood-brain barrier. Circ Res 59:216-220

60. Faraci FM, Mayhan WG, Schmid PG, Heistad DD 1988 Effects of arginine vasopressin on cerebral microvascular pressure. Am J Physiol 255:H70-H76

61. Shenker Y 1989 Atrial natriuretic hormone and aldosterone regulation in saltdepleted state. Am J Physiol 257:H583-H587

62. Koehler RC, Jones Jr MD, Traystman RJ 1982 Cerebral circulatory response to carbon monoxide and hypoxic hypoxia in the lamb. Am J Physiol 243:H27-H32

63. Rosenberg AA, Jones Jr MD, Traystman RJ, Simmons MA, Molteni RA 1982 Response of cerebral blood flow to changes in $\mathrm{PCO}_{2}$ in fetal, newborn, and adult sheep. Am J Physiol 242:H862-H866

64. Sola A, Spitzer AR, Morin III FC, Schlueter MA, Phibbs RH 1983 Effects of arterial carbon dioxide tension on the newborn lamb's cardiovascular responses to rapid hemorrhage. Pediatr Res 17:70-76

65. Hansen NB, Nowicki PT, Miller RR, Malone T, Bickers RG, Menke JA 1986 Alterations in cerebral blood flow and oxygen consumption during prolonged hypocarbia. Pediatr Res 20:147-150

66. Jones Jr MD, Traystman RJ 1984 Cerebral oxygenation of the fetus, newborn, and adult. Semin Perinatol 8:205-216 